\title{
Preliminary analysis of distributed in situ soil moisture measurements
}

\author{
L. Brocca, M. Galli, and M. Stelluti \\ National Research Council, IRPI, Via Madonna Alta, 126, Perugia, Italy \\ Received: 25 November 2004 - Revised: 2 March 2005 - Accepted: 4 March 2005 - Published: 31 March 2005
}

\begin{abstract}
Surface soil moisture content is highly variable in both space and time. Remote sensing can provide an effective methodology for mapping surface moisture content over large areas but ground based measurements are required to test its reliability and to calibrate retrieval algorithms. Recently, we had the opportunity to design and perform an experiment aimed at jointly acquiring measurements of surface soil water content at various locations and remotely sensed hyperspectral data. The area selected for the experiment is located in central Umbria and it extends for $90 \mathrm{~km}^{2}$. For the area, detailed lithological and multi-temporal landslide inventory maps were available. We identified eight plots where measurements of soil water content were made using a Time Domain Reflectometer (TDR). The plots range in size from $100 \mathrm{~m}^{2}$ to $600 \mathrm{~m}^{2}$, and cover a variety of topographic and morphological settings. The TDR measurements were conducted during four days, on 5 April, 15 April, 2 May and 3 May 2004. On 3 May the NERC airborne CASI 2 acquired the hyperspectral data. Preliminary analysis concerning the matching between the landslides and the soil moisture were reported. Statistical and geostatistical analysis investigating the spatial-temporal soil moisture distribution were performed. These results will be compared with the data of surface temperature obtained from the remotely sensed hyperspectral sensor.
\end{abstract}

\section{Introduction}

Quantitative information on soil moisture before and during a rainfall event is an important information to forecast the time and location of shallow landslides (Campbell, 1975; Crosta and Frattini, 2003) and floods (Goodrich et al., 1994). This information is difficult to obtain, because the classical point measurements techniques (e.g., Time Domain Reflectometry, gravimetric, geoelectric) are unable to cover large areas.

Correspondence to: L. Brocca

(brocca@irpi.cnr.it)
To fill this gap, attempts have been made to determine soil moisture conditions in the upper layer of the soil using remote sensing techniques spanning the range of frequencies from optical to microwaves (Pietroniro and Prowse, 2002). A limitation of remotely sensed data to ascertain soil moisture from satellite or airborne sensors lays in the lack of quantitative ground measurements of water content (Famiglietti et al., 1999). In May 2004, we performed a campaign aimed at acquiring in situ soil moisture measurements to be correlated with remotely sensed hyperspectral data. In this paper we report on the field measurements, including a preliminary analysis of the obtained data.

\section{Study area}

We performed the experiment in a $90 \mathrm{~km}^{2}$ area in Umbria, Central Italy, located between the towns of Collazzone and Todi. For the area, a detailed lithological map, a multitemporal landslide inventory map, and a land use map, were available to us. The lithological map and the multi-temporal inventory map were prepared at 1:10 000 scale though extensive field studies aided by the interpretation of multiple sets of aerial photographs (Fig. 1). In the area the following rock types crop out: (I) alluvial deposit, (II) talus deposit, (III) travertine deposit, (IV) continental deposit, (V) gravel, (VI) sand, (VII) clay, (VIII) layered sandstone and marl, and (IX) layered limestone.

We measured volumetric soil moisture at eight sites (yellow squares in Fig. 1) using a Time Domain Reflectometer (TDR). At each site, systematic soil moisture measurements were obtained on square or rectangular plots ranging from $100 \mathrm{~m}^{2}(10 \mathrm{~m} \times 10 \mathrm{~m})$ to $600 \mathrm{~m}^{2}(20 \mathrm{~m} \times 30 \mathrm{~m})$ in size, and covering different topographic settings, from flat to sloping terrain. Some of the plots were selected to cross the boundary of recent landslides. TDR measurements were conducted on grids of $1 \times 1,2 \times 2$ or $4 \times 4 \mathrm{~m}$. For each plot we obtained from 96 to 176 TDR measurements, for a total of 2781 soil moisture data. TDR measurements were also made along profiles 


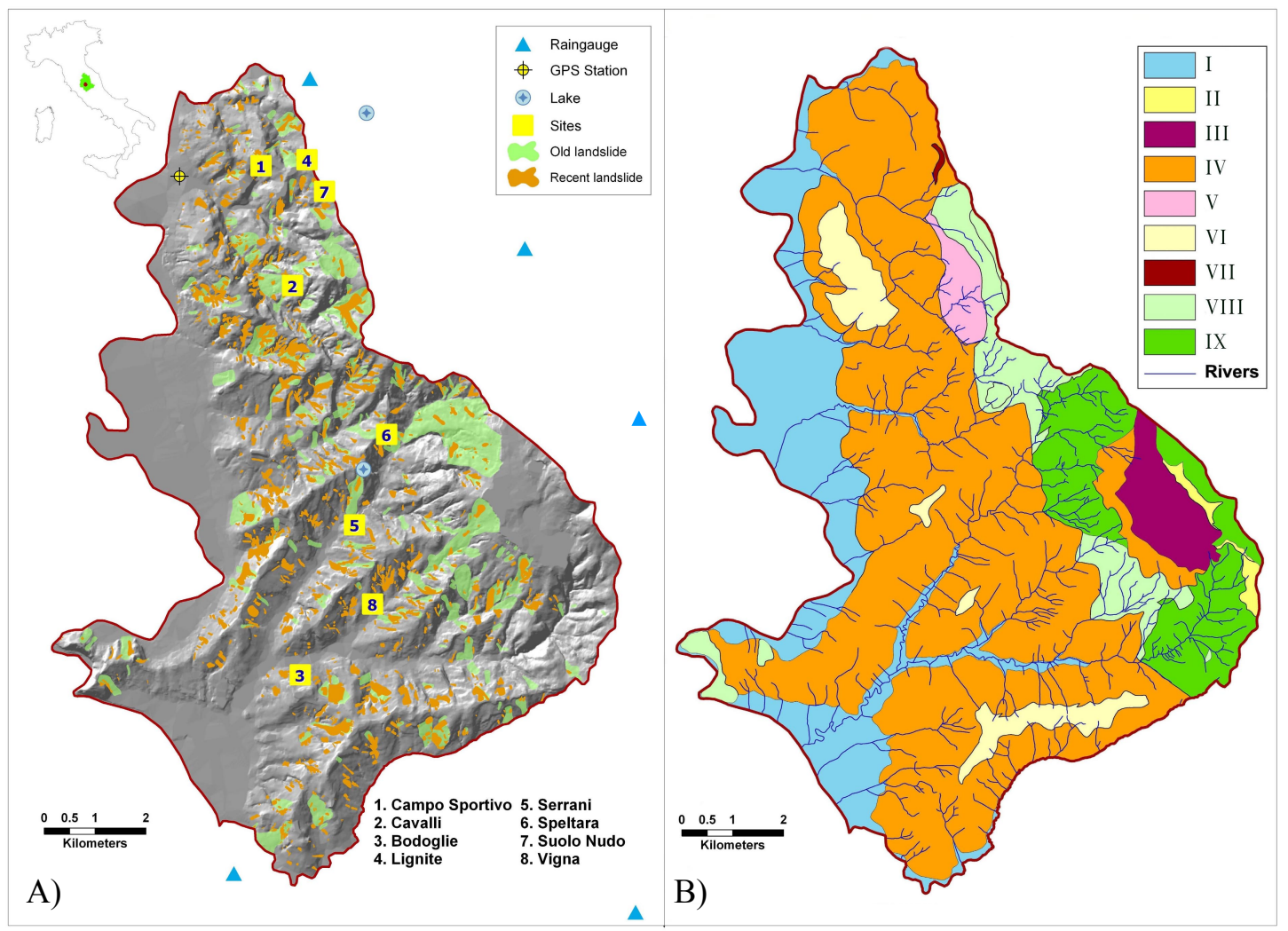

Fig. 1. Study area with location of investigated sites. Landslides and lithology are shown. A) Landslides inventory map. Numbers corresponds to site ID. B) Lithological map: (I) alluvial deposit, (II) talus deposit, (III) travertine deposit, (IV) continental deposit, (V) gravel, (VI) sand, (VII) clay, (VIII) layered sandstone and marl, and (IX) layered limestone.

joining two plots, or following the local steepest slope. Profiles were from 100 to $150 \mathrm{~m}$ long. Measurements along the profiles were made every 4 or $5 \mathrm{~m}$. The TDR campaign was conducted on 5 April, 15 April, 2 May and 3 May 2004. This was a wet period in Umbria. Cumulative rainfall for several raingauges exceeded $130 \mathrm{~mm}$, larger than the long term average for the period (74.2 $\mathrm{mm}$ at the raingauge of Todi).

On 3 May 2004 the NERC airborne CASI-2 hyperspectral system was flown over the area. Simultaneously, a LIDAR obtained detailed elevation data. The airborne hyperspectral and lidar data are not yet available to us. During the fly, we measured water surface temperature in two small artificial lakes located inside (Fig. 1) and outside of the study area. Measurements of water surface temperature will be used to calibrate the remotely-sensed hyperspectral data. In the TDR instrument used to measure volumetric soil moisture stainless-steel wave guides were $15 \mathrm{~cm}$ long and spaced $5 \mathrm{~cm}$, encompassing a volume of soil of about $750 \mathrm{~cm}^{3}$. To precisely locate the soil moisture measurements, we used two double-frequency GPS receivers. GPS measurements were conducted at a rate of 1 per second.

\section{Preliminary analysis}

Our preliminary analysis of the available soil moisture data consists of: a) comparison between landslides and the soil moisture maps; b) statistical analysis of the measurements; c) geostatistical analysis of the measurements.

We first compare the spatial (geographic) distribution of soil moisture map with the location of existing landslides. For the purpose we prepared soil moisture maps for each site. The maps were obtained through inverse distance weighted (IDW) interpolation of the point TDR measurements. Selection of a simple interpolation method - compared to more sophisticated interpolation techniques, e.g. Kriging - was made because for this work we were interested in matching the soil moisture patterns with the landslides boundaries.

In Figs. 2, 3, and 4 we show the results for three sites, where soil moisture measurements were made in areas where recent landslides have occurred. The location of landslides was known from the interpretation of multiple sets of areal photographs flown in the period from 1941 to 1997.

At the "LIGNITE" site (\#4) we measured soil moisture along four profiles, $4 \mathrm{~m}$ apart, aligned along the slope local maximum gradient (Fig. 2). Measurements revealed a central zone of higher soil moisture content (a "wet" zone), shown in dark blue colours in Fig. 2c. We attribute the higher water 


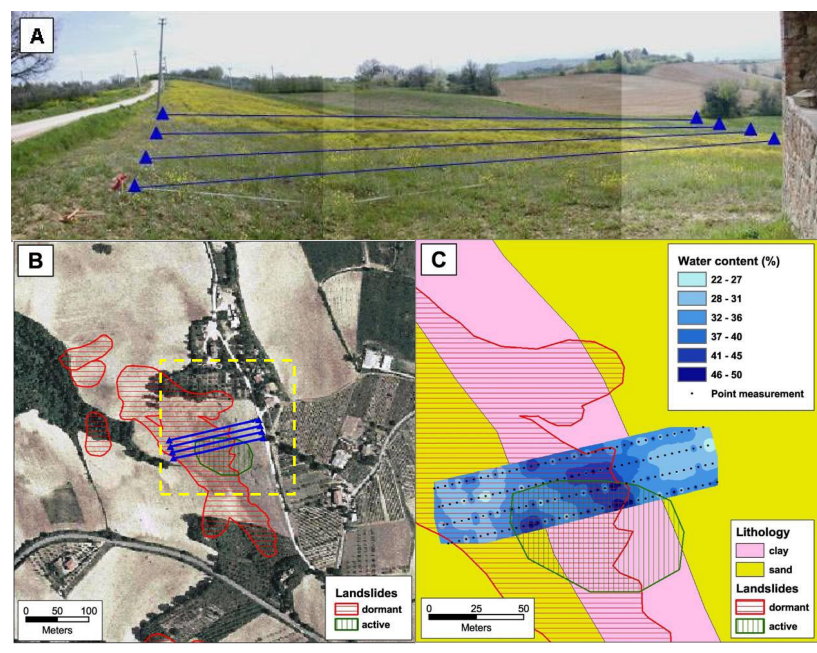

Fig. 2. Lignite site, \#4. A) View of the study area. Triangles show limits of four profiles. B) Orthophoto map showing landslide deposits (hatched lines) and transects (blue lines). Yellow dashed line shows extent of enlargement. C) Enlargement showing lithology and soil moisture geographic variability.

content in the soil to the presence of a layer of lignite, which most probably also controls the location of the landslide.

At the "CAMPO SPORTIVO" site (\#1) we measured soil moisture on two $10 \mathrm{~m} \times 10 \mathrm{~m}$ grids located inside (1) and outside (2) a landslide deposit, and along three profiles, two of which connected the two grids (Fig. 3a). A third profile was made along the slope local maximum gradient, mostly inside the landslide deposit. Inside the two grids we obtained measurements every $1 \mathrm{~m}$. Along the profiles measurements were made every $5 \mathrm{~m}$. Average values of soil moisture inside and outside the landslide deposit were different, with a distinct increase of soil moisture at the landslide boundary. Inspection of Fig. 3c reveals that along the down-slope profile, as one may expect, soil moisture increases down hill and inside the landslide deposit.

At the "CAVALLI" site (\#2) we measured soil moisture on two $40 \mathrm{~m} \times 12 \mathrm{~m}(1)$ and $30 \mathrm{~m} \times 20 \mathrm{~m}$ (2) grids, located at a distance of $90 \mathrm{~m}$, and along two $164 \mathrm{~m}$ long profiles (3). Inside the two grids we obtained measurements every $2 \mathrm{~m}$, and along the profiles every $4 \mathrm{~m}$. The upper grid (1) crossed a landslide boundary (Fig. 4). In this grid, soil moisture exhibits a distinct increase at the landslide boundary. The lower grid (2) is located entirely inside the landslide deposit, making the interpretation of the soil moisture measurements controversial. Higher values of soil moisture are located near to the landslide boundary. Along the profiles (3) soil moisture correlates with lithological types and a landslide crown area. Higher values of soil water content were observed where clay crops out. Note that the lithological boundary corresponds to a landslide boundary.

Our next step is to compare the ensemble of soil moisture measurements statistically. Figure 5 shows box plots of soil moisture measurements conducted at eight sites in the study

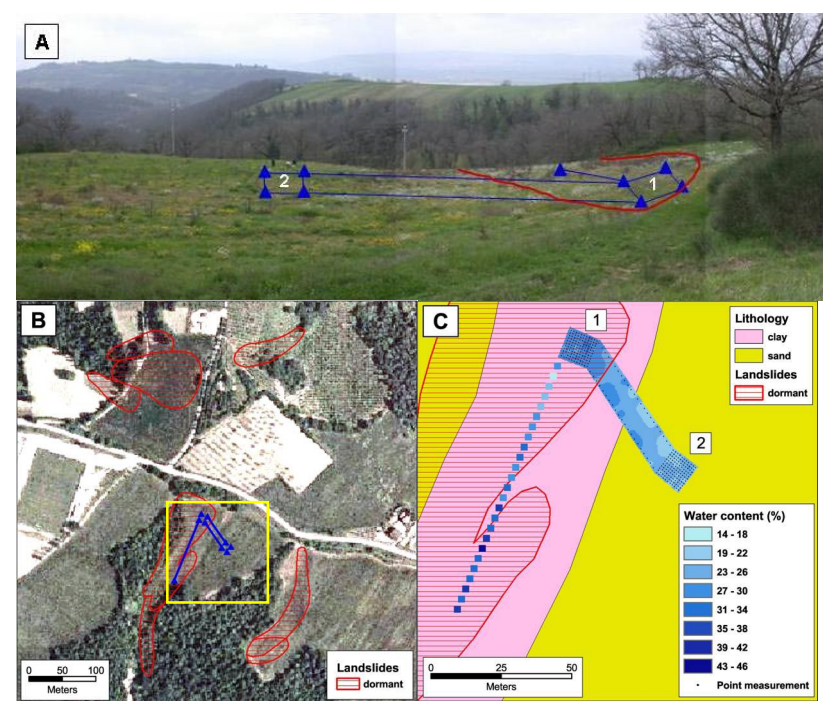

Fig. 3. Campo Sportivo site, \#1. A) View of the study area. Triangles show limits of the grids and of the profiles. B) Orthophoto map showing landslide deposits (hatched lines) and transects (blue lines). Yellow dashed line shows extent of enlargement. C) Enlargement showing lithology and soil moisture spatial variability.

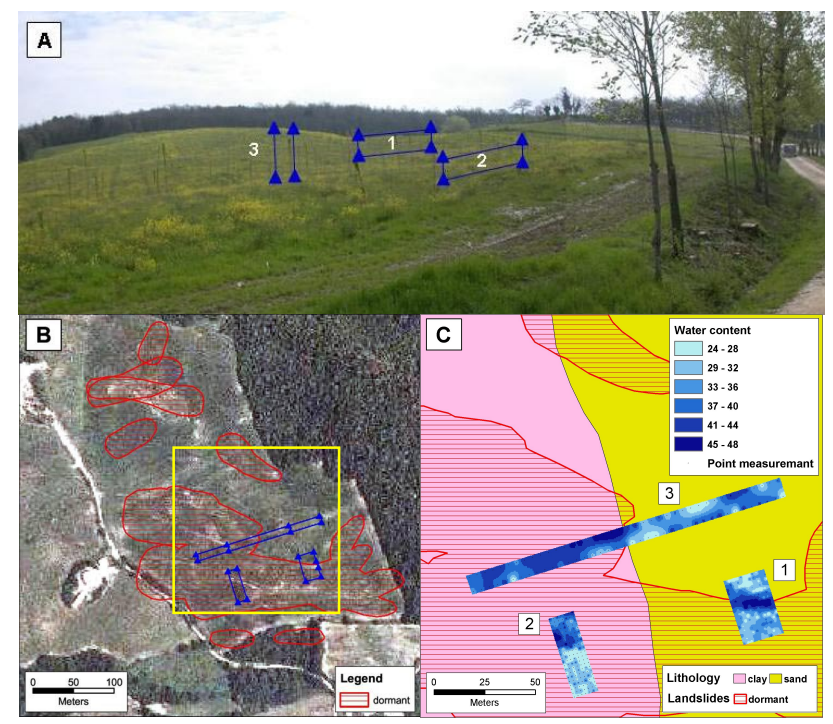

Fig. 4. Cavalli site, \#2. A) View of the study area. Triangles show limits of the grids and of the profiles. B) Orthophoto map showing landslide deposits (hatched lines) and profiles (blue lines). Yellow dashed line shows extent of enlargement. C) Enlargement showing lithology and soil moisture spatial variability.

area. The graph shows: i) the main lithological type (clay, silt, sand), ii) the position of the plots with respect to the slope, iii) whether measurements were made inside or outside a landslide, and iv) the date of the measurements.

Inspection of Fig. 5 reveals that measurements obtained on 5 April are consistently lower that those obtained on 2 May, and measurements made on 3 May were systematically higher than those obtained the day before. A weak 

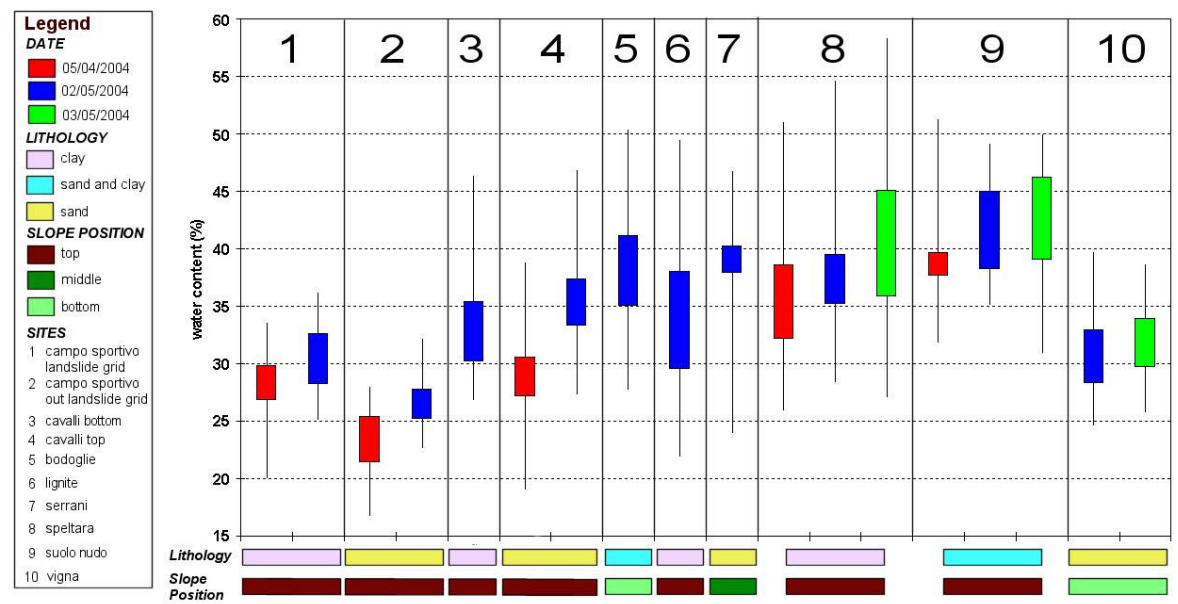

Fig. 5. Box plot of water content measurements at 10 sites. See Fig. 1 for site location.
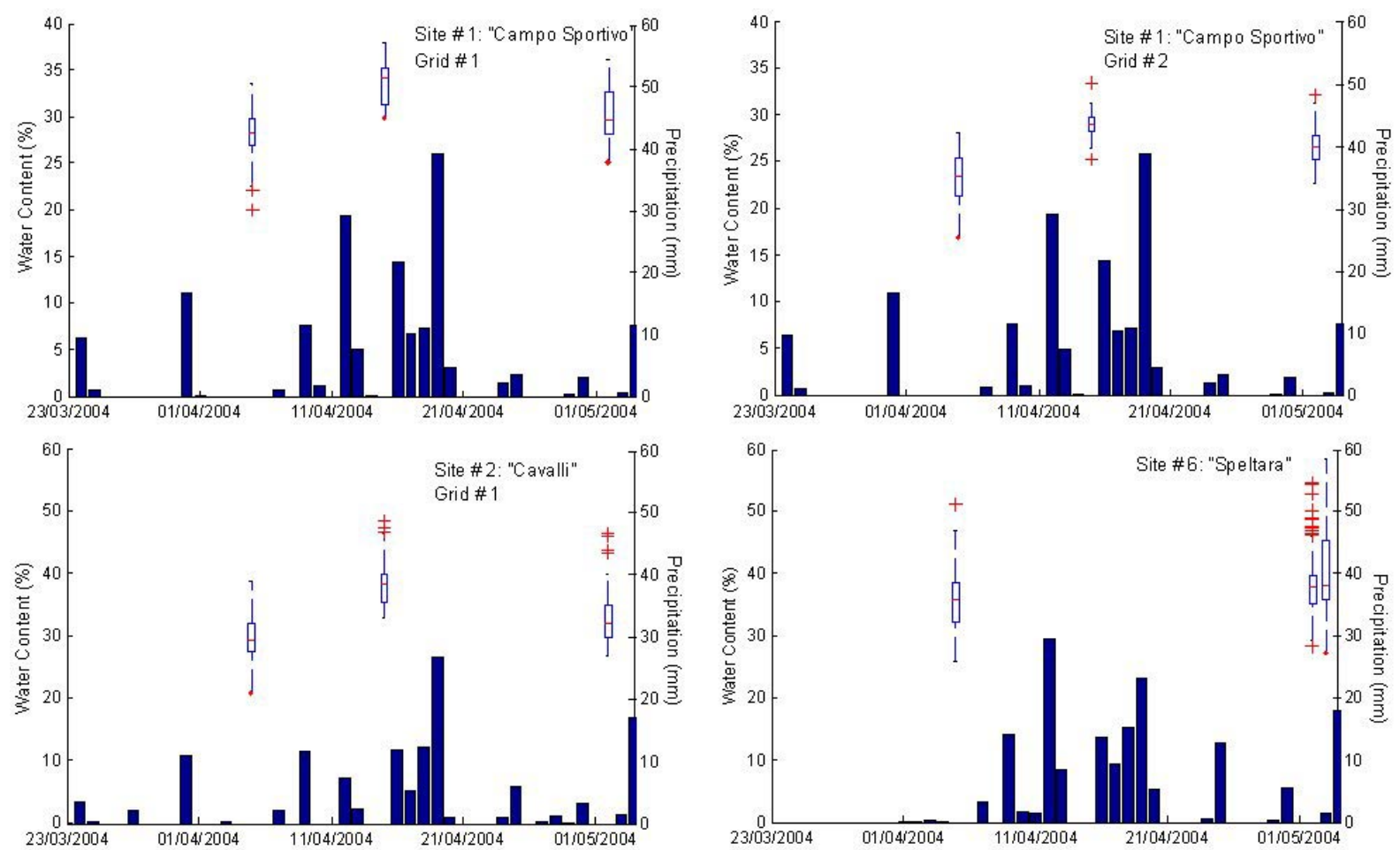

Fig. 6. Correlation between daily precipitation (histogram, right y axis) and soil moisture conditions (box plot, left y axis) for 3 sites. See Fig. 1 for site location.

correlation exists between lithological types and soil moisture, with clay deposits exhibiting higher values. No clear correlation exists with the position of the measurements on the slope. Statistical tests revealed that the measured soil moisture data do not follow a normal, log-normal or extreme value (Gumbel) distribution. Coefficient of variation was 0.11 , in agreement with other field campaigns conducted in Central Italy (Brocca et al., 2004).

Figure 6 shows box plots of soil moisture measurements along with the time series of the daily precipitation at 3 sites. The first set of measurements on 4 April was made after a relatively dry period, while the other set of measurements were obtained during or after a wet period. The latter measurements are characterized by an higher soil moisture content.

To further explore soil moisture spatial variability, we computed variograms for plots exceeding $300 \mathrm{~m}^{2}$ in size (Fig. 7). We obtained a correlation length ranging between 10 and $35 \mathrm{~m}$, in agreement with published results for sites not involved in slope failures (Petrone et al., 2004; Western et al., 2004). 


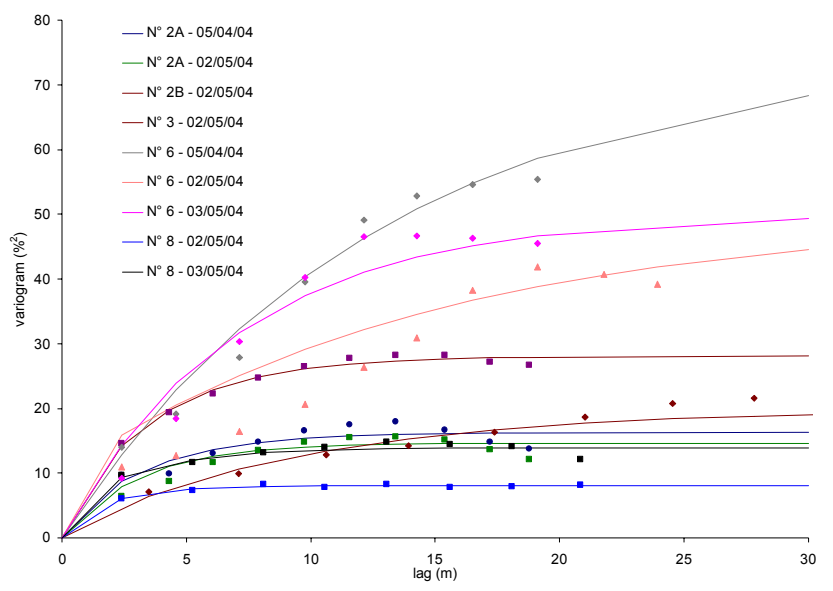

Fig. 7. Variograms of measuring plots with area greater than $300 \mathrm{~m}^{2}$. Symbols represent sample variograms and solid lines the theoretical exponential models.

Finally, Fig. 8 shows the spatial distribution of soil moisture for the SPELTARA site (\#6). At this site we obtained repeated measurements on the same $30 \mathrm{~m} \times 10 \mathrm{~m}$ grid. Measurements were made on 5 April, 2 May and 3 May 2004. Combined analysis of the three maps reveals that the spatial pattern of soil moisture remains similar, even if the absolute values of soil moisture change. Determination coefficient $(\mathrm{R})$ between the soil moisture measurements carried out at the same point varies between 0.7 and 0.8 . We obtained similar results for all the plots for which repeated measurements are available.

\section{Conclusions}

The preliminary analysis of the available soil moisture data allows us to derive some general conclusion.

We observed a distinct (relative) variation in the values of the measured soil moisture at the boundary of existing landslides. In general, soil moisture exhibits lower values inside and outside a landslide deposit, possibly depending on lithology, and higher values at the landslide boundary. We tentatively explain this by the presence of fractures at the boundary between the stable ground and the landslide. Geostatistical analysis conducted on the larger test sites revealed a spatial correlation length of soil moisture of about 10-35 m with an average of $20 \mathrm{~m}$. This is in agreement with measurements conducted in northern Umbria (Brocca et al., 2004). Where TDR measurements were repeated two or three times, the absolute values of the measured soil moisture changed, but the geographical trend remained the same. Areas identified as relatively more "wet" or "dry" during one set of measurements remained "wet" and "dry" in the other measurements. This is linked mainly to the local soil characteristics and to the presence/absence of landslides boundaries and subordinately to the position on the slope, mainly for the measurements carried out along profiles. Vegetation at each

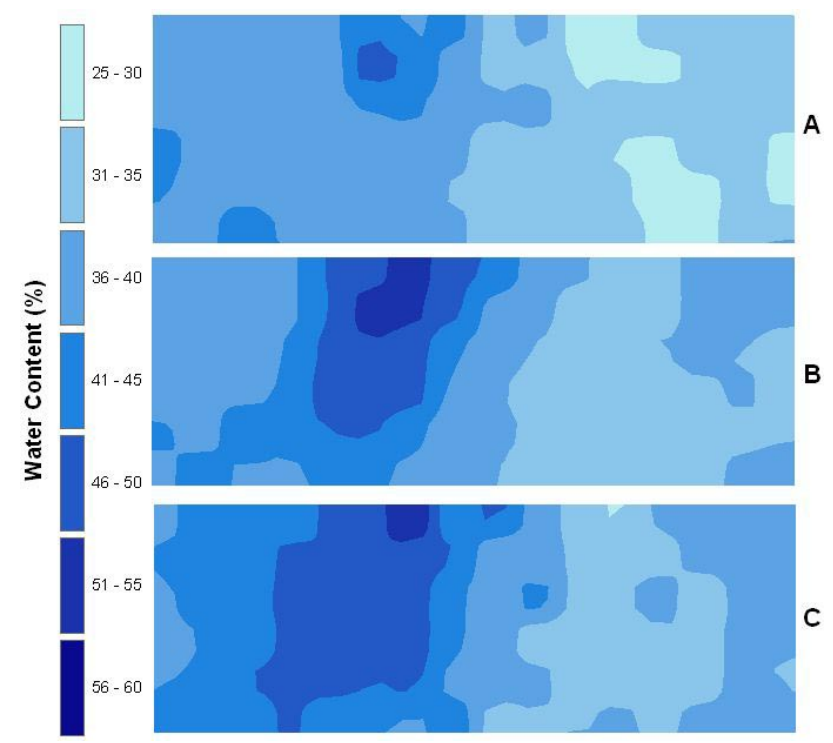

Fig. 8. Soil moisture maps (Inverse distance weight method) for the "SPELTARA" site (\#6) and for 3 different dates. A) 5 April 2004, B) 2 May 2004, C) 3 May 2004. Colours indicate percentage of water in the soil, from $25 \%$ (light blue) to $60 \%$ (dark blue).

sites is nearly uniform, and we don't have information of soil moisture variability due to the land cover characteristics.

Soil moisture measurements carried out in this study were mostly addressed to the validation of the hyperspectral data obtained by NERC. To further investigate the correlation between soil moisture in the upper layer of the soil and the presence or absence of landslides, we are designing a new campaign of field measurements. In this campaign data will be acquired on much larger grids covering an entire slope, but at a coarser resolution, otherwise higher cost would be required. The aim of the new campaign is to validate the relationship between soil moisture and the boundaries of the landslides highlighted in this study, for an entire slope. Furthermore, because we observed a temporal persistency of the soil moisture temporal pattern, we can use this information, together with the one already available, to compared at a larger scale the superficial water content and the estimate of ground surface temperature obtained from the remotely-sensed hyperspectral sensor, when this information will become available.

Acknowledgements. We thank the many participants, too numerous to list, that assisted with the data collection. This study would not have been possible without their efforts.

Edited by: L. Ferraris

Reviewed by: F. Caparrini and another referee 


\section{References}

Brocca, L., Melone, F., and Moramarco, T.: Soil water content monitoring in an experimental basin in Central Italy, Euromediterranean Conference ERB04, 13-17 Ottobre 2004, Torino, 2004.

Campbell, R. H.: Soil slips, debris flow, and rainstorm in the Santa Monica mountains and vicinity, southern California, US Geological Survey, Professional Paper 851, 1975.

Crosta, G. B. and Frattini, P.: Distributed modelling of shallow landslides triggered by intense rainfall, Nat. Haz. Earth Sys. Sci., 3, 81-93, 2003,

SRef-ID: 1684-9981/nhess/2003-3-81

Goodrich, D. C., Schmugge, T. J., Jackson, T. J., Unkrich, C. L., Keefer, T. O., Parry, R., Bach, L. B., and Amer, S. A.: Runoff simulation sensitivity to remotely sensed initial soil water content, Water Resour. Res., 30, 1393-1406, 1994.
Famiglietti, J. S., Devereaux, J. A., Laymon, C. A., Tsegaye, T., Houser, P. R, Jackson, T. J., Graham, S. T., Rodell, M., and van Oevelen, P. J.: Ground-based investigation of soil moisture variability within remote sensing footprints during the Southern Great Plains 1997 (SGP97) Hydrology Experiment, Water Resour. Res., 35, 1839-1851, 1999.

Petrone, R. M., Price, J. S., Carey, S. K., and Waddington, J. M.: Statistical characterization of the spatial variability of the soil moisture in a cutover petland, Hydrological Process, 18, 41-52, 2004.

Pietroniro, A. and Prowse, T. D.: Applications of remote sensing in hydrology, Hydrological Processes, 16, 1537-1541, 2002.

Western, A. W., Zhou, S., Grayson, R. B., McMahon, T. A., Blöschl, G., and Wilson, D. J.: Spatial correlation of soil moisture in small catchments and its relationship to dominant spatial hydrological processes, Journal of Hydrology, 286, 113-134, 2004. 